\title{
High Temperature Stability of an Al-Zr-Ti Alloy Prepared using Gas Atomization and Spark Plasma Sintering Technology
}

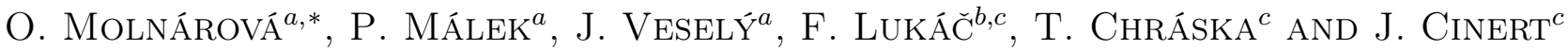 \\ ${ }^{a}$ Department of Physics of Materials, Faculty of Mathematics and Physics, \\ Charles University, Prague, Czech Republic \\ ${ }^{b}$ Department of Low-Temperature Physics, Faculty of Mathematics and Physics, \\ Charles University, Prague, Czech Republic \\ ${ }^{c}$ Institute of Plasma Physics of the CAS, Prague, Czech Republic
}

\begin{abstract}
The aim of this study was to prepare an aluminium alloy with high temperature stability using the powder metallurgical route. Gas atomized powder of the $\mathrm{Al}-\mathrm{Zr}-\mathrm{Ti}$ alloy was consolidated by the spark plasma sintering (SPS) technology. The fine grained structure (grain size between 2 and $3 \mu \mathrm{m}$ ) observed in the gas atomized powder was retained after sintering both at $425^{\circ} \mathrm{C}$ and $550{ }^{\circ} \mathrm{C}$. The microhardness of $49 \mathrm{HV}$ observed in the gas atomized powder was increased up to about $100 \mathrm{HV}$ in the SPS compacts. Precipitation of the $\mathrm{Al}_{3}(\mathrm{Zr}, \mathrm{Ti})$ phase during sintering can explain this strengthening. The materials stability was tested by annealing at temperatures above $450^{\circ} \mathrm{C}$. The grain size remained stable even after $10 \mathrm{~h}$ of annealing. A decrease in microhardness by about $20 \%$ can be attributed especially to the formation of the stable modification of the $\mathrm{Al}_{3}(\mathrm{Zr}, \mathrm{Ti})$ phase.
\end{abstract}

DOI: 10.12693 /APhysPolA.134.876

PACS/topics: 81.05.Bx, 81.20.Ev, 81.40.Cd, 64.75.Op

\section{Introduction}

Aluminium alloys, due to their high specific strength, are frequently used in commercial applications. The main drawback of age hardenable $\mathrm{Al}$ alloys is that they cannot be used at temperatures above about $423 \mathrm{~K}$ as they lose their strength due to coarsening or dissolution of strengthening particles. In order to develop an $\mathrm{Al}$ alloy with a strength stable at higher temperatures the alloy composition and the producing method have to be properly chosen. It is necessary to use alloying elements that can form small, homogeneously distributed particles of intermetallic phases resistant to coarsening and dissolution. These particles serve as dislocation pinners and contribute to high strength. Simultaneously, they can pin the grain boundaries and suppress the grain growth which might contribute to a stability of strength.

The main criteria for the selection of appropriate alloying elements are a very low solid solubility in $\mathrm{Al}$ matrix up to high temperatures, a low diffusion rate, and an ability to form particles of intermetallic phases with a low lattice mismatch between the formed intermetallic compound and the $\mathrm{Al}$ matrix. Alloying elements like $\mathrm{Fe}, \mathrm{Ni}, \mathrm{Ti}, \mathrm{V}$ or $\mathrm{Zr}$ fit the above mentioned criteria [1]. Zirconium has the slowest diffusion rate among them [2] and low solid solubility with a maximum of

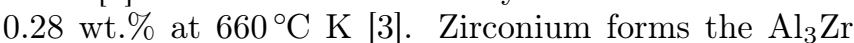
phase. This $\mathrm{Al}_{3} \mathrm{Zr}$ phase appears in two modifications.

*corresponding author; e-mail: mopersze@gmail.com
The stable phase with the structure $\mathrm{DO}_{23}$ is preceded by a metastable phase of $\mathrm{L}_{2}$ structure, which has a lower lattice mismatch compared to the stable phase. This reduced mismatch, according to the theory of the diffusion controlled particle coarsening, leads to increased stability of these second-phase particles. Further additives like $\mathrm{V}$, Hf or Ti are supposed to substitute $\mathrm{Zr}$ atoms in the elemental cell of $\mathrm{Al}_{3} \mathrm{Zr}$ particles and to reduce the lattice mismatch to $\mathrm{Al}$ matrix. It was shown in [4] that the lattice mismatch of the metastable $\mathrm{Al}_{3}\left(\mathrm{Zr}_{0.7} \mathrm{Ti}_{0.3}\right)$ phase is practically zero and these particles should be extremely resistant to coarsening.

It is generally accepted that gas atomization (as a typical rapid solidification technique) can suppress formation of coarse primary particles during solidification, leads to supersaturated solid solution and metastable second phase particles [1]. To preserve the benefits from gas atomization in bulk materials a suitable consolidation method with minimal influence on materials microstructure has to be chosen. Spark Plasma Sintering (SPS) combines uniaxial pressure with heating by low voltage DC current flowing through the sample [5]. The high current densities and large Joule heat evolved primarily at powder particle surfaces whereas the powder particle interiors remain nearly unaffected. The high heating rates and short holding times used in SPS limit undesirable changes in rapidly solidified microstructure, like eg. solute reorganization or recrystallization.

The aim of this investigation was to study the high temperature stability of an $\mathrm{Al}-\mathrm{Zr}-\mathrm{Ti}$ alloy prepared by the powder metallurgy (PM) route. Microstructure and microhardness of powders and two SPS compacts pre- 
pared using different SPS parameters were examined. The high temperature stability of the prepared SPS compacts was studied by annealing between 450 and $500{ }^{\circ} \mathrm{C}$.

\section{Experimentals}

The nitrogen atomized AlZr2.6Ti0.7 (in wt.\%) powder sieved down to $50 \mu \mathrm{m}$ was supplied by Nanoval $\mathrm{GmbH}$ \& Co. KG, Berlin. The average powder particle size was $20.3 \mu \mathrm{m}$ according to the producer. The powders were sintered using a pulsed electric current sintering system - model FCT SPS-HP25 (FCT Systeme GmbH). During consolidation, the samples were free heated up to $400^{\circ} \mathrm{C}$, the sintering temperature was then reached with a heating rate of $25^{\circ} \mathrm{C} / \mathrm{min}$, and simultaneously the uniaxial pressure was increased. The holding time was $4 \mathrm{~min}$ and then the compact was free cooled. The following combinations of sintering temperature and applied stress were used: $425^{\circ} \mathrm{C} / 100 \mathrm{MPa}$ and $550^{\circ} \mathrm{C} / 80 \mathrm{MPa}$.

The microstructure was investigated by scanning electron microscopy (SEM) in back scattered electron mode (BSE) using an FEI Quanta 200F equipped with field emission cathode. Grain size and grain orientations were analysed using electron backscatter diffraction (EBSD). The OIM software was employed for EBSD analysis. Transmission electron microscopy (TEM) investigations were performed using JEOL 220FS microscope operating at $200 \mathrm{kV}$. TEM samples from powder particles were produced using focused ion beam milling in Zeiss Auriga Compact SEM microscope. From SPS compacts, the discs with a diameter of $3 \mathrm{~mm}$ were cut parallel to the SPS load direction and thinned electrochemically using a double jet polisher Tenupol-5 under $15 \mathrm{~V}$ at $-15^{\circ} \mathrm{C}$ in the solution of $33 \%$ nitric acid in methyl alcohol. The phase composition was verified by X-ray diffraction (XRD) using a diffractometer D8 Discover (Bruker AXS). Quantitative Rietveld analysis was performed in TOPAS V5 in order to estimate the weight fraction of present phases.

Materials strength was characterised by Vickers microhardness measured using an automatic microhardness tester Qness Q10A+. The load of $10 \mathrm{~g}$ was applied at powder material where 15 different powder particles were tested. The load of $50 \mathrm{~g}$ was applied to compact samples, where the average microhardness values were determined from 20 indentations.

\section{Results}

The microstructure of mostly spherical gas atomized powder particles was found dependent on the particle size. The smallest powder particles seemed to exhibit a segregation free microstructure and were mostly single crystalline. Larger particles were found to have a cellular microstructure with intercellular regions depleted of $\mathrm{Zr}$ and $\mathrm{Ti}$ (see the smaller powder particle on Fig. 1a).
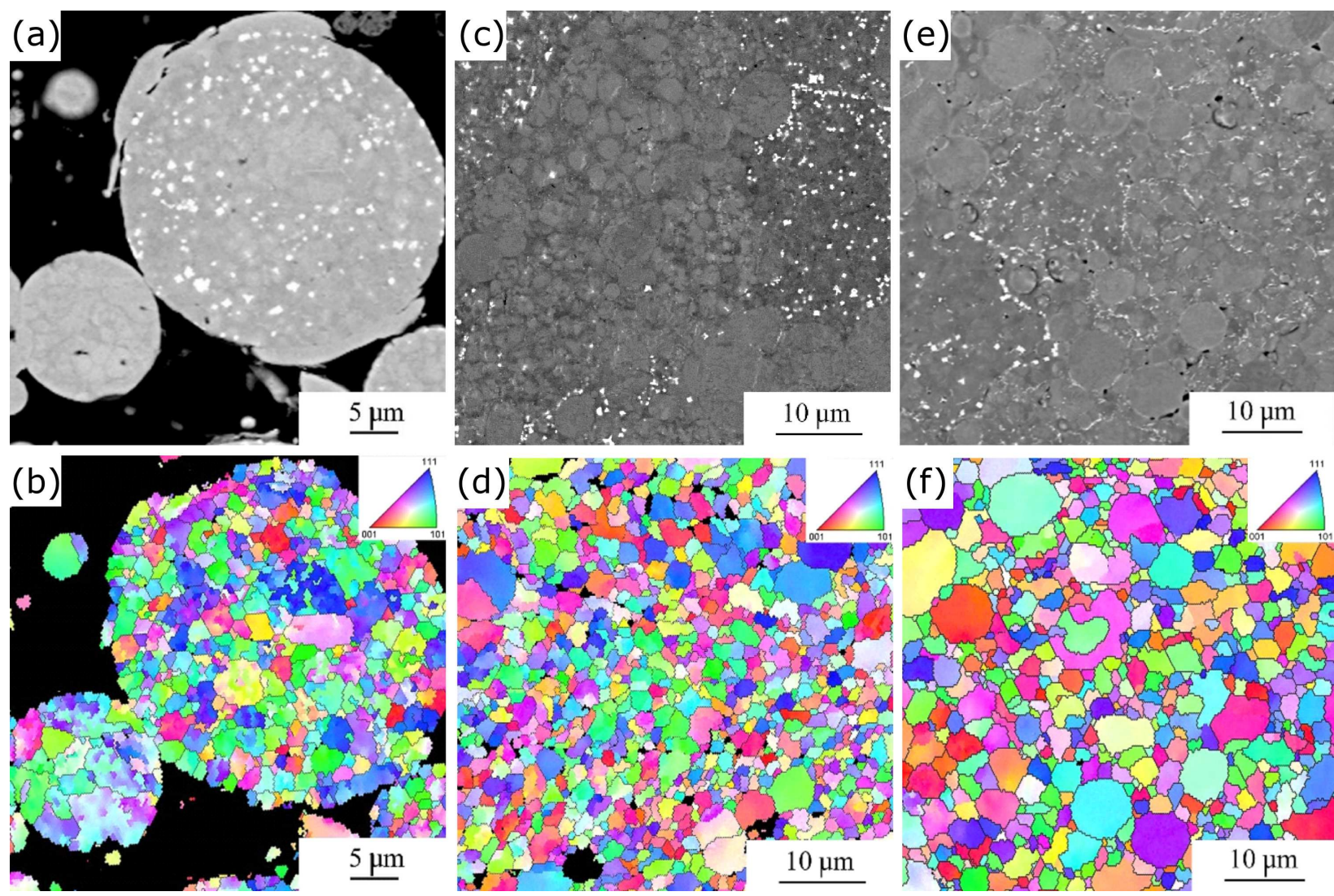

Fig. 1. The BSE contrast and the corresponding EBSD micrographs of the gas atomized powder (a, b), SPS compact $425^{\circ} \mathrm{C} / 100 \mathrm{MPa}(\mathrm{c}, \mathrm{d})$, and SPS compact $550^{\circ} \mathrm{C} / 80 \mathrm{MPa}(\mathrm{e}, \mathrm{f})$. 

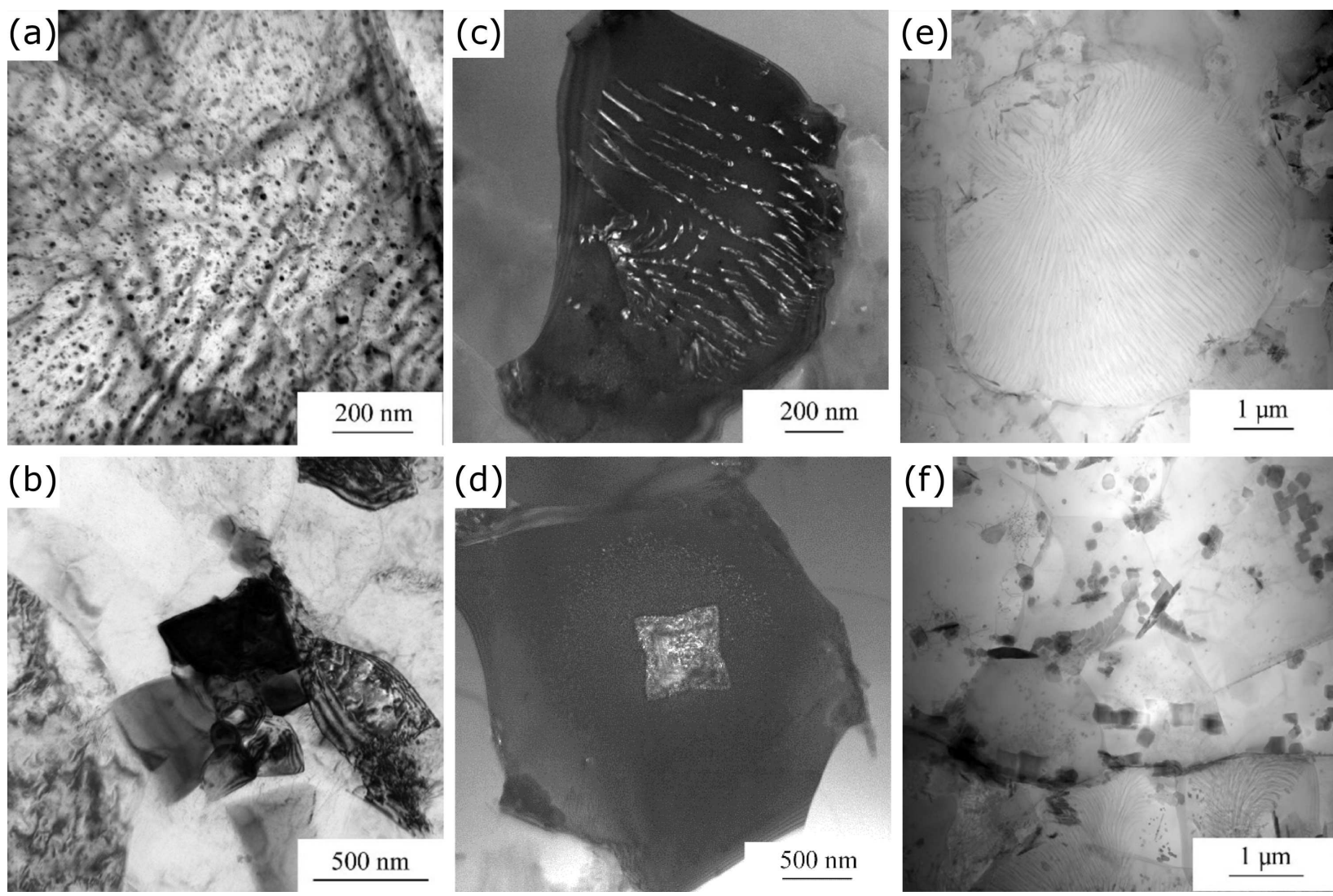

Fig. 2. Precipitates present in the gas atomized powder $(\mathrm{a}, \mathrm{b})$, in the SPS compact $550{ }^{\circ} \mathrm{C} / 80 \mathrm{MPa}$ (in dark field contrast mode) (c, d), and in the SPS compact $550^{\circ} \mathrm{C} / 80 \mathrm{MPa}$ after annealing $1 \mathrm{~h} / 500^{\circ} \mathrm{C}(\mathrm{e}, \mathrm{f})$ taken by transmission electron microscopy.

The largest powder particles were polycrystalline and contained a large quantity of primary coarse cuboidal or petal-like $\mathrm{Al}_{3}(\mathrm{Zr}, \mathrm{Ti})$ particles (Figs. 1a, b). The average grain size of the powder material was between 2 and $3 \mu \mathrm{m}$. XRD measurements proved the presence of only metastable $\mathrm{L}_{2} \mathrm{Al}_{3}(\mathrm{Zr}, \mathrm{Ti})$ phase $(3.2 \mathrm{wt} . \%)$ in the powder material. The microstructure of both SPS compacts (Figure 1c and 1e) was similar to that of the powder material and the original powder particles were still recognisable. The former largest powder particles became deformed around the smaller ones. The compacts average grain size is similar to that found in the powder material. XRD investigation revealed that sample compacted at $425^{\circ} \mathrm{C}$ contained only the $\mathrm{L} 1_{2}$ phase (1.3 wt.\%), whereas the sample sintered at $550^{\circ} \mathrm{C}$ contained beside the $\mathrm{L} 1_{2}$ phase (1.3 wt.\%) also the $\mathrm{DO}_{23}$ phase $(1.3 \mathrm{wt} . \%)$. The relatively low microhardness $(49 \pm 12 \mathrm{HV})$ observed in the atomized powder was increased up to $103 \pm 8 \mathrm{HV}$ by SPS at $425^{\circ} \mathrm{C}$ and up to $90 \pm 8 \mathrm{HV}$ by SPS at $550{ }^{\circ} \mathrm{C}$.

The detailed TEM investigation of the atomized powder revealed the presence of both very fine (the size in the range of $10 \mathrm{~nm}$ ) and coarse petal-like precipitates (the size slightly below $1 \mu \mathrm{m})$ of the metastable $\mathrm{L}_{2} \mathrm{Al}_{3}(\mathrm{Zr}, \mathrm{Ti})$ phase (Figs, 2a, b). The compacts were found to contain beside the $\mathrm{nm}$ sized spherical and the coarser petal-like particles also precipitates of $\mathrm{Al}_{3}(\mathrm{Zr}, \mathrm{Ti})$ arranged into fans
(Figs. 2c, d). Rod shaped particles of $\mathrm{L}_{2}$ structure were also observed. In the SPS $550^{\circ} \mathrm{C} / 80 \mathrm{MPa}$ compact a remarkable quantity of rod shaped particles with the $\mathrm{DO}_{23}$ structure was observed.

TABLE I

The influence of isochronal annealing $(1 \mathrm{~h})$ on microhardness and grain size of the SPS $425^{\circ} \mathrm{C} / 100 \mathrm{MPa}$ compact

\begin{tabular}{c|c|c|c|c}
\hline \hline Annealing at & None & $450^{\circ} \mathrm{C}$ & $475^{\circ} \mathrm{C}$ & $500^{\circ} \mathrm{C}$ \\
\hline $\mathrm{HV}$ & $103 \pm 8$ & $99 \pm 9$ & $93 \pm 9$ & $88 \pm 9$ \\
$d[\mu \mathrm{m}]$ & $2.5 \pm 0.8$ & $2.3 \pm 0.7$ & $2.1 \pm 0.6$ & $2.6 \pm 0.8$
\end{tabular}

Table I brings the microhardness and grain size values for the SPS $425^{\circ} \mathrm{C} / 100 \mathrm{MPa}$ compact after isochronal annealing for $1 \mathrm{~h}$ at 450,475 and $500^{\circ} \mathrm{C}$. Microhardness retained its value after annealing at $450^{\circ} \mathrm{C}$, higher annealing temperatures resulted in a slight decrease. The grain size remained unaffected, but the wt.\% of the $\mathrm{L}_{2}$ phase gradually increased. The fraction of the stable $\mathrm{DO}_{23}$ phase was under the detectability limit in all samples. The influence of isothermal annealing at $500{ }^{\circ} \mathrm{C}$ is documented in Table II for both SPS compacts. The microhardness of both SPS compacts decreased with increasing annealing time, however, this process was slower in the $425^{\circ} \mathrm{C} / 100 \mathrm{MPa}$ compact. The grain size was stable even after a long-term annealing. 
The influence of isothermal annealing at 500 on microhardness, grain size and

TABLE II second phase particle content of both SPS compacts

\begin{tabular}{c|l|c|c|c|c}
\hline \hline & Annealing time & Non-annealed & $1 \mathrm{~h}$ & $5 \mathrm{~h}$ & $10 \mathrm{~h}$ \\
\hline & microhardness [HV] & $103 \pm 8$ & $88 \pm 9$ & $83 \pm 6$ & $78 \pm 5$ \\
$\mathrm{SPS} 425^{\circ} \mathrm{C} /$ & $d[\mu \mathrm{m}]$ & $2.5 \pm 0.8$ & $2.6 \pm 0.8$ & $2.5 \pm 0.8$ & $2.7 \pm 0.8$ \\
$100 \mathrm{MPa}$ & $\mathrm{L}_{2}[$ wt.\%] & 1.3 & 0.8 & 1.3 & 1.2 \\
& $\mathrm{DO}_{23}[\mathrm{wt} . \%]$ & 0 & 0 & 1.7 & 1.8 \\
\hline & microhardness [HV] & $90 \pm 8$ & $76 \pm 7$ & $76 \pm 6$ & $70 \pm 6$ \\
$\mathrm{SPS} 550^{\circ} \mathrm{C} /$ & $d[\mu \mathrm{m}]$ & $3.1 \pm 1.0$ & $3.1 \pm 1.1$ & $3.2 \pm 1.0$ & $2.9 \pm 0.9$ \\
$80 \mathrm{MPa}$ & $\mathrm{L}_{2}[$ wt.\%] & 1.3 & 1.3 & 1.0 & 1.4 \\
& $\mathrm{DO}_{23}[\mathrm{wt} . \%]$ & 1.3 & 1.9 & 2.7 & 2.2
\end{tabular}

An increase in the quantity of the stable $\mathrm{DO}_{23}$ phase was observed in the SPS $550^{\circ} \mathrm{C} / 80 \mathrm{MPa}$ compact already after 1 hour of annealing. In the SPS $425^{\circ} \mathrm{C} / 100 \mathrm{MPa}$ compact, the formation of the stable $\mathrm{DO}_{23}$ phase was delayed.

The heat treatment of SPS compacts led to solute reorganization. The small nm sized spherical phases present in small powder particles were found to retain their $\mathrm{L} 1_{2}$ structure but transformed to fan shaped structure (see Fig. 2e), however there were also areas where the spherical small particles retained or both the small spherical ones and the fan shaped structures were present. Beside the coarse primary petal-like particles and fan arrangement a lot of rods, both $\mathrm{L}_{2}$ and $\mathrm{DO}_{23}$ structure, were also observed as it is presented on Figure $2 \mathrm{f}$. Dislocations were found to be pinned by second phase particles (Fig. 2f).

\section{Discussion}

As mentioned in the introduction, the $\mathrm{Al}-\mathrm{Zr}-\mathrm{Ti}$ alloy should meet the requirements for achieving stable high strength at elevated temperatures. A segregation free supersaturated matrix represents the best precursor for reaching high strength. Such a microstructure cannot be achieved using chill casting as coarse primary particles are formed already during casting [6]. It has been shown previously that neither the high solidification rate in gas atomization or melt spinning process can result in a completely micro-segregation free microstructure [4, 7]. However, the formation of coarse particles can be suppressed and a refined microstructure can be formed.

The powder particles of different sizes solidified at different cooling rates and their microstructure is, therefore, also different. In peritectic alloys, like the $\mathrm{Al}-\mathrm{Zr}-\mathrm{Ti}$ alloy, the solute rich phase is the first one formed during equilibrium solidification. The primary particles then act as heterogeneous nuclei during solidification of solute depleted melt. During rapid solidification the high undercooling can led to cellular structure where cells are solute-rich and intercellular regions are depleted of solutes [8]. With increasing powder particle size a transition from the cellular microstructure to a microstructure with primary intermetallic particles can occur [8]. The gradient of cooling rate from the surface to the centre of droplet can cause further microstructural inhomogeneity. The formation of coarse primary particles was observed preferentially at the powder particle surface. The microhardness of the powder material can be measured only in the largest powder particles containing numerous primary particles. Therefore, the microhardness value is much smaller than that of the melt-spun material of similar composition [9]. The inhomogeneity of the microstructure is also responsible for the high standard deviation of microhardness measurement on powder particles. The lower strength of larger powder particles helps in sintering as these powder particles can deform during sintering, fill in the space, and reduce the resulting porosity.

The microstructural heterogeneity was preserved also in the SPS compacts as the short thermal exposure during SPS minimized the influence on powders microstructure. The original powder particles are still recognisable unlike the material prepared from the atomized powder by hot extrusion [7] where the original microstructure was completely lost and replaced by hot-worked microstructure due to the long heat influence. The microhardness of the SPS $425^{\circ} \mathrm{C} / 100 \mathrm{MPa}$ compact increased due to precipitation of predominantly metastable $\mathrm{L}_{2} \mathrm{Al}_{3}(\mathrm{Zr}, \mathrm{Ti})$ phase. The value close to $100 \mathrm{HV}$ is much higher than that of the hot extruded material $(55 \mathrm{HV})$ [7] and comparable with the value of the meltspun material annealed at $425{ }^{\circ} \mathrm{C}$ for 1 hour [9]. A lower microhardness of the SPS $550^{\circ} \mathrm{C} / 80 \mathrm{MPa}$ compact reflects the presence of coarser precipitates of the stable $\mathrm{DO}_{23} \mathrm{Al}_{3}(\mathrm{Zr}, \mathrm{Ti})$ phase.

The transition of the $\mathrm{L}_{2}$ to the $\mathrm{DO}_{23}$ phase occurs at high temperatures after a long heat exposure. In cast $\mathrm{Al}-0.1 \mathrm{Zr}$ and $\mathrm{Al}-0.1 \mathrm{Zr}-0.1 \mathrm{Ti}$ alloys this transition did not appear up to $450^{\circ} \mathrm{C}$, it started at $525^{\circ} \mathrm{C}$ after extended aging times [10]. As shown in [11] SPS at $450^{\circ} \mathrm{C}$ caused no transition, whereas higher sintering temperatures led to the formation of the stable phase. Especially this phase transition is responsible for a decrease in microhardness during a long term annealing at $500^{\circ} \mathrm{C}$. The stable $\mathrm{DO}_{23}$ phase has a larger lattice misfit to the matrix which can result in a faster coarsening of these precipitates and, consequently, to a reduction in strength. Despite of these changes in phase composition the grain size remained nearly constant. 
Based on the current findings further investigations concentrating on the reduction of the powdered materials grain size using high energy ball milling will follow. The reduced grain size is hoped to be retained also in the SPS compact, leading to an increment in materials microhardness. Simultaneously, it can be expected that high energy milling might destroy some coarse primary particles present in the atomized material and form a better precursor for the precipitation of the metastable $\mathrm{Al}_{3}(\mathrm{Zr}, \mathrm{Ti})$ phase.

\section{Conclusion}

Both the gas atomized powder and the sintered compacts exhibited a non-homogeneous microstructure. The $\mathrm{Al}_{3}(\mathrm{Zr}, \mathrm{Ti})$ particles of different shape (petal-like, dots, fan arrangement, rods) were observed. The relatively low sintering temperature $\left(425^{\circ} \mathrm{C}\right)$ suppressed the transition of $\mathrm{L}_{2}$ to $\mathrm{DO}_{23}$ phase. The formation of $\mathrm{DO}_{23}$ phase was not detected after annealing up to $500^{\circ} \mathrm{C}$ for $1 \mathrm{~h}$. During a longer heat treatment at $500^{\circ} \mathrm{C}$ a gradual evolution of the stable $\mathrm{DO}_{23}$ phase occurred. The precipitation of the metastable modification contributes to microhardness increase, the transformation to the stable modification reduces it.

\section{Acknowledgments}

This work was supported by the Czech Science Foundation under grant GACR 15-15609S and by the project "Nanomaterials centre for advanced applications", Project No. CZ.02.1.01/0.0/0.0/15_003/0000485, financed by ERDF.

\section{References}

[1] H. Jones, Aluminium 54, 274 (1978).

[2] S.K. Das, L.A. Davis, Mater. Sci. Eng. 98, 1 (1988).

[3] L. Mondolfo, Aluminium Alloys: Structure and properties, Butterworth, London 1976.

[4] P. Málek, M. Janeček, B. Smola, P. Bartuška, Kovové Mater. 17, 386 (1999) (in Czech).

[5] M. Suárez, A. Fernández, J.L. Menéndez, R. Torrecillas, H.U. Kessel, J. Hennicke, R. Kirchner, T. Kessel, in Sintering Applications, Ed. B. Ertug; InTech, Rijeka, Croatia 2013, p. 319

[6] E. Nes, H. Billdal, Acta Metall. 25, 1031 (1977).

[7] P. Málek, M. Janeček, P. Bartuška, Kovové Mater. 40, 371 (2002).

[8] N.J.E. Adkins, N. Saunders, P. Tsakiropoulos, Mater. Sci. Eng. 98, 217 (1988).

[9] P. Málek, M. Janeček, B. Smola, Kovové Mater. 38, 160 (2000).

[10] K.E. Knipling, D.C. Dunand, D.N. Seidman, Acta Mater. 56, 1182 (2008).

[11] O. Molnárová, P. Málek, F. Lukáč, T. Chráska, J. Cinert, in: Proc. of the METAL 201\%: 26th Int. Conf. on Metallurgy and Materials, Brno (Czech Republic), 2017, p. 1066. 